\title{
Factor 4/10/20/130: A Briefing Note
}

Nick Barter and Jan Bebbington (University of St Andrews)

At a conference recently a speaker was advocating that the efficiency of automobiles could be improved by a factor of 20 and, by implication, if this was achieved then environmental limits would not be breached. This short note seeks to respond to such a proposition and proceeds along three lines. First, exactly what factor 20 entails is outlined. Second, an evaluation of whether or not factor 20 will be sufficient given our environmental challenges will be explored. Finally, we will suggest that factors of efficiency (regardless of whether then are sufficiently large given our environmental challenges) miss important secondary questions of equity, among other things.

Weisacker, Lovins and Lovins” (1998, p. xiv) outline "50 examples of quadrupling resource productivity ... [to demonstrate the] broad feasibility of Factor Four” efficiency gains. What they are saying is that where currently a single unit of resource might give a single unit of output, an efficiency gain of factor four would give four units of output for the one unit of input. Weisacker, Lovins and Lovins (1998) suggest that this means that "we can live twice as well - yet use half as much” (ibid: xviii). The following table demonstrates this using numbers. Following Weisacker, Lovins and Lovins’s (1998) reasoning for factor four, a factor 20 efficiency gain would result in realising 20 times output for each unit of input.

\begin{tabular}{|c|c|c|c|c|}
\hline & \multicolumn{4}{|c|}{ Output } \\
\hline $\begin{array}{c}\text { Resource/Input } \\
\text { Unit }\end{array}$ & Factor & Factor & Factor & Factor \\
\hline 1 & $\mathbf{2}$ & $\mathbf{3}$ & $\mathbf{4}$ \\
\hline 0.5 & 1 & 2 & 3 & 4 \\
\hline 0.25 & 0.5 & 1 & 1.5 & 2 \\
\hline
\end{tabular}

Assuming that it is technologically feasible to achieve factor 20 gains, whether or not factor 20 is a sufficient level of gain needs to be addressed. In this context, our example will 
change slightly which will itself highlight a possible limitation of the factor improvement conceptualisation.

In the above examples, factor improvements have been described in terms of resource input/output relationships. Resource use, however, only captures part of the impact of economic activities. Significant improvements will also be required with regard to the relationship between a unit of output and pollution impacts. It is possible to re-phrase this relationship such that if each unit of pollution generates one unit of output, the same unit of pollution will achieve a much higher level of output if factor improvements are achieved. The following example of how we might determine if factor 20 is a sufficient level of efficiency gain will be played out looking at the relationship between greenhouse gas emissions and economic activity.

In our current policy context, it is accepted that we need to reduce greenhouse gas emissions by $80 \%$ by 2050 (based on a 1990 baseline measure) in order to avoid 'dangerous climate change'. ${ }^{1}$ Using the language of efficiency gains, if one unit of carbon provided one unit of output in 1990 then by 2050 the same output will be required from only 20\% of the carbon input. Applying factor thinking to this equation, an $80 \%$ reduction in input whilst achieving the same output requires a 'factor 5' improvement.

On the surface, such a calculation suggests that a factor 20 improvement (as was asserted could be achieved for automobiles) would allow global climate change targets to be met. This analysis, however, is based on the status quo not changing. It does not, for example, take account of any growth in output due to rising living standards and/or a growing population. If either of these things happen, keeping to the 2050 targets efficiency gains will require higher efficiency gains. How much higher is addressed by the following analysis that seeks to incorporate both growth and an equity requirement into the factoring process.

\footnotetext{
${ }^{1}$ Schellnhuber, J. (2006) defines climate change to be 'dangerous' where average global temperatures rises exceed 2 degrees Celsius. At this point it is anticipated that there will be discontinuities (or tipping points) in the climate system which will lead to large scale alteration of how the earth functions which will be significantly detrimental to human populations.
} 
Jackson (2009, p. 53-57) models the impact of likely growth in greenhouse emissions (as driven by growth in population) to 2050 as well as factoring in what impact a desire to achieve equity for all those alive in the future would do (each assumption is considered in more detail in what follows). To benchmark equity, Jackson (2009) uses the level of EU prosperity enjoyed in 2007. This benchmark has been chosen on the assumption that most people are unlikely to agree to reduce their levels of consumption below what they currently enjoy. At the same time, a commitment to sustainable development implies a commitment to both inter and intra generational equity. Over time, this implies that average living standards will converge: albeit that we are unsure of what level that convergence will be at. As a result, the calculations made below could use any measure of living standard. A lower level than that assumed will lead to a lower efficiency gain requirement, and vice versa. In addition, to simplify the analysis Jackson (2009) focuses on carbon dioxide emissions (which will under estimate the efficiency gains required for greenhouse gas emissions to fall to levels previously specified).

World carbon dioxide intensity, as measured by grams of $\mathrm{CO}_{2}$ per US dollar of output (measured in constant 2000 dollars) was $768 \mathrm{gCO}_{2} / \$$ in 2007. If we assume that by 2050 we need to bring emissions into line with a $450 \mathrm{ppm}^{2}$ target, that globally we will have 9 billion people alive at that time ${ }^{3}$ and that growth will continue along its current trend (approximately $2 \% \mathrm{pa})^{4}$ then we need to bring emissions down to $36 \mathrm{gCO}_{2} / \$$ to ensure environmental limits

\footnotetext{
${ }^{2}$ This means that there will be 450 parts of $\mathrm{CO}_{2}$ per million in the atmosphere. The Intergovernmental Panel on Climate Change estimates that stabilising emissions between 445 and 490 ppm will result in a global temperature may rise of between 2 and 2.4 degrees Celsius. As previously mentioned, the goal of 450ppm is thus linked to 'dangerous' climate change thresholds and it also corresponds to the $80 \%$ reduction target for 2050 .

${ }^{3}$ Population estimates are based on UN data that is compiled by the population division of the Department of Economic and Social Affairs. This division tracks the various factors that contribute to population levels (including disease and mortality profiles, fertility rates, income and education impacts on family sizes and such like) as well as documenting and modelling population movements. Their estimates for future population range from 7.8 billion to 10.8 billion with the 'usual' mid point of 9 billion being quoted as the likely population in 2050. Until we reach 2050 we will not be clear of how accurate their estimates are and at the same time, there may yet be unforeseen events that will decrease (rather than increase) the human population. It is usual, however, to use the 9 billion estimate as the most likely future size of the human family.

${ }^{4}$ Projections of the future size of the world economy usually assume that there will be continued economic growth. The reason this assumption is made is that the world economy currently requires economic growth to operate. As we have seen recently, if growth is not forthcoming then economies go into recession (with knock on social and economic impacts). Jackson (2009) questions the wisdom of this commitment to growth (as we would) but without radical re-design of economic institutions this level of growth is a minimum that is required to avoid global recession.
} 
are not breached. Further, if we put equity into the equation and hence assume that all people alive will have incomes that are the same as the $2007 \mathrm{EU}$ average income, then we need to move to a position where we emit just $6 \mathrm{gCO}_{2} / \$ .^{5}$ Taking the factoring language used above, this is a factor 130 efficiency gain.

Of course, there is no way in which to know if all these numbers are 'correct'. The point here is not so much about whether or not these various assumptions (which are all based on considerable data gathering and interpretation) are right or wrong. Rather, the point of the calculation is to sketch out some of the complexities that have to be considered when trying to figure out what efficiency gains are likely to be sufficient for the task in hand. For this particular set of assumptions, the factor efficiency gain that will be needed is factor 130 . Importantly, these calculations also take sustainable development as the normative frame of reference and as such equity becomes important. This is not to say that everyone will or should earn the same amount of money under sustainable development criteria but that average incomes across the globe will be broadly the same for each country.

There are several implications that arise from these calculations and which should be raised when 'factor 20 will sort us out' type statements are made. First, while factor 20 sounds good, the question must be asked is this a sufficient level of efficiency gain for the environmental targets that need to be pursued. As is evident from the above calculation (taking into account the provisos offered) factor 20 falls well short of that which is necessary with respect to $\mathrm{CO}_{2}$ emissions. Second, whether or not continued economic and population growth is factored into equations should be asked. If they are not, then there has to be a plausible reason why these long run trends have been ignored because, as has been demonstrated, these factors radically change the outcome sought. Third, if we have a commitment to sustainable development (that is, if one takes equity seriously) then some decision about where income levels should and will stabilise has to be made (these may be lower or higher than those enjoyed currently in the developed world). Finally, and returning to the automobile example, there may be other considerations that need to be considered when deciding if growth in car ownership and use is appropriate. For example, even if

\footnotetext{
${ }^{5}$ These calculation are made by starting with current emissions per unit of output and factoring in emissions reductions required to fit with the $450 \mathrm{ppm}$ target, the likely increase in population, the consumption level rise given more people along with a general increase in consumption via growth in the economy. If you change any of those elements (and all are open to change) then the factor efficiency required would also change.
} 
efficiency gains could be achieved so that growth in driving could be ecologically sustainable it may not be socially or economically sustainable to have a growth in a particular activity. For example, congestion remains an economic cost and the loss of public space to roads remains a relevant social issue regardless of how efficient a car is. Efficiency, therefore, may be a necessary but not sufficient step in terms of sustainable development.

In summary, we hope that his short piece provides a context within which to put claims of factor efficiency gains that appear to 'solve' our environmental problems. While not dismissing such gains, we would argue that we need to know if such gains are likely to be sufficient given the goals we have for environmental impact as well as understanding what assumptions are being made (most importantly about equity) when efficiency gains are offered up as solutions. As has been demonstrated, factor 5 rapidly becomes factor 130 if a particular set of assumptions are made in terms of population, income levels and emissions targets. The difference, therefore, matters.

\section{References}

Jackson, T. (2009), Prosperity Without Growth? (Sustainable Development Commission: Scotland).

Schellnhuber, J. (2006) Avoiding Dangerous Climate Change. (Cambridge: Cambridge University Press)

Weizsacker, E. V., Lovins, A. B., Lovins, L. H. (1998) Factor Four: Doubling Wealth, Halving Resource Use. (Earthscan: London). 